\title{
Role of Moisture Transport and Recycling in Characterizing Droughts: Perspectives from Two Recent U.S. Droughts and the CFSv2 System ${ }^{\circ}$
}

\author{
Tirthankar Roy, ${ }^{\mathrm{a}}$ J. Alejandro Martinez, ${ }^{\mathrm{b}}$ Julio E. Herrera-Estrada, ${ }^{\mathrm{a}, \mathrm{c}}$ Yu Zhang, ${ }^{\mathrm{d}}$ \\ Francina Dominguez, ${ }^{\mathrm{e}}$ AleXis Berg, ${ }^{\mathrm{a}}$ Mike Ek ${ }^{\mathrm{f}, \mathrm{g}}$ AND ERIC F. WOOD ${ }^{\mathrm{a}}$ \\ ${ }^{a}$ Department of Civil and Environmental Engineering, Princeton University, Princeton, New Jersey \\ ${ }^{\mathrm{b}}$ Escuela Ambiental, Universidad de Antioquia, Medellin, Colombia \\ ${ }^{\mathrm{c}}$ Department of Earth System Science, Stanford University, Stanford, California \\ ${ }^{\mathrm{d}}$ One Concern, Inc., Palo Alto, California \\ ${ }^{\mathrm{e}}$ Department of Atmospheric Sciences, University of Illinois at Urbana-Champaign, Urbana, Illinois \\ ${ }^{\mathrm{f}}$ NOAA/National Centers for Environmental Prediction/Environmental Modeling Center, College Park, Maryland \\ ${ }^{\mathrm{g}}$ National Center for Atmospheric Research, Boulder, Colorado
}

(Manuscript received 4 August 2018, in final form 19 November 2018)

\begin{abstract}
We investigate the role of moisture transport and recycling in characterizing two recent drought events in Texas (2011) and the Upper Midwest (2012) by analyzing the precipitation, evapotranspiration, precipitable water, and soil moisture data from the Climate Forecast System version 2 (CFSv2) analysis. Next, we evaluate the CFSv2 forecasts in terms of their ability to capture different drought signals as reflected in the analysis data. Precipitation from both sources is partitioned into recycled and advected components using a moisture accounting-based precipitation recycling model. All four variables reflected drought signals through their anomalously low values, while precipitation and evapotranspiration had the strongest signals. Drought in Texas was dominated by the differences in moisture transport, whereas in the Upper Midwest, the absence of strong precipitation-generating mechanisms was a crucial factor. Reduced advection from the tropical and midlatitude Atlantic contributed to the drought in Texas. The Upper Midwest experienced reduced contributions from recycling, terrestrial sources, the midlatitude Pacific, and the tropical Atlantic. In both cases, long-range moisture transport from oceanic sources was reduced during the corresponding drought years. June and August in Texas and July and August in the Upper Midwest were the driest months, and in both cases, drought was alleviated by the end of August. Moisture from terrestrial sources most likely contributed to alleviating drought intensity in such conditions, even with negative anomalies. The forecasts showed noticeable differences as compared to the analysis for multiple variables in both regions, which could be attributed to several factors as discussed in this paper.
\end{abstract}

\section{Introduction}

\section{a. Recent droughts in Texas and the Upper Midwest}

Severe drought associated with high temperatures affected Texas and the Upper Midwest during the summer of 2011 and 2012 (Karl et al. 2012). In the central United States, the severity of the drought was the worst since the Dust Bowl of the 1930s (Schubert et al. 2004), causing crop failures, job losses, water shortages,

Supplemental information related to this paper is available at the Journals Online website: https://doi.org/10.1175/JHM-D18-0159.s1.

Corresponding author. Tirthankar Roy, tirthankar.roy@princeton.edu energy impacts, navigation problems, and environmental losses (Grigg 2014) and endangering international grain markets (Boyer et al. 2013).

In Texas and the northern part of Mexico, drought started emerging in the fall of 2010, due primarily to a La Niña event in the tropical Pacific Ocean (Seager et al. 2014). The forecast models predicted transient eddy moisture flux divergence related to a northward shift of the Pacific-North American storm track; however, the observed drought was related to mean flow moisture divergence and drying over the southern plains and southeastern United States, as a result of negative North Atlantic Oscillation pattern during the 2010/11 winter (Seager et al. 2014). Texas experienced record dry conditions from March to August in 2011, with much lower 12-month rainfall total (October 2010-September 
2011) as compared to the climatology (statewide driest $5 \%$ with the exception of north and east Dallas), and summer temperatures reaching close to the warmest (over $5^{\circ} \mathrm{F}$ above the long-term average) statewide temperature ever recorded in the United States (NielsonGammon 2012).

Hoerling et al. (2014) argued that the 2012 drought over the central plains was primarily due to the natural variations in weather, triggered by the absence of rainfall-producing mechanisms, such as the springtime low pressure systems and the associated warm and cold fronts that usually result in widespread rains or thunderstorms and cause the majority of precipitation in July and August. The Gulf of Mexico moisture transport was reduced, following decreased cyclones and frontal activity in late spring, while the upper troposphere sustained the anomalous high pressure that inhibited the formation of convective rainfall due to increased subsidence and stability of the atmosphere (Hoerling et al. 2014). Mallya et al. (2013) argued that La Niña caused weaker winter storms in the United States during 2011, which resulted in the 2012 drought in the Upper Midwest.

\section{b. Precipitation recycling}

The contribution of evapotranspiration from a region to the same region's precipitation is defined as precipitation/moisture recycling. The recycling ratio (ratio between recycled precipitation and total precipitation) is used as a diagnostic to quantify the strength of landatmosphere interactions or coupling. Precipitation recycling can be a key component of land-atmosphere coupling, which plays a crucial role in determining the extent and severity of extreme climatic conditions such as droughts (Findell and Eltahir 2003). Depending on the geographic location, time of year, and the spatial scale of modeling, the recycled precipitation can be as high as $25 \%$ of the total precipitation (Dominguez et al. 2008).

Modeling atmospheric moisture transport to identify different sources and sinks can be classified into three different categories: analytical or box models, numerical water vapor tracers, and physical water vapor tracers, that is, isotopes [see Gimeno et al. (2012) for a comprehensive review]. In this study, we use an analytical modeling approach. Analytical recycling models have evolved over the last several decades, starting from one-dimensional models (Savenije 1995; Budyko 1974) to more detailed, higher-dimensional representations (Burde and Zangvil 2001; Bo et al. 1994; Brubaker et al. 1993; Schär et al. 1999; Trenberth 1999). One of the major shortcomings of earlier models was that they all assumed negligible moisture storage, and therefore were suitable only for monthly or seasonal time scales. Zangvil et al. (2004) proposed a recycling model that could be applied to a daily time scale, which showed the importance of relaxing the assumption of negligible moisture storage. Dominguez et al. (2006) proposed a two-dimensional precipitation recycling model, termed the Dynamic Recycling Model (DRM), based on the conservation of atmospheric water vapor and relaxing the assumption of negligible moisture storage, which was later extended by Martinez and Dominguez (2014) to account for the relative contributions of different sources to a given sink. The DRM has been a popular choice recently for studying the characteristics of precipitation recycling in different parts of the world (Bisselink and Dolman 2008; DeAngelis et al. 2010; Pathak et al. 2017; Hua et al. 2016, 2017; Agudelo et al. 2018; Mei et al. 2015).

\section{c. Objectives}

The role of precipitation recycling in drought occurrence and drought dynamics has been a growing area of research (Dominguez et al. 2009; Herrera-Estrada et al. 2017; Roundy et al. 2013; Herrera-Estrada 2017). Although previous studies have looked at the potential causes of the recent droughts in Texas and the Upper Midwest, the role of precipitation recycling in influencing different characteristics of these drought events has just begun to be explored (Herrera-Estrada 2017). This study is twofold. In the first part, we use the DRM to investigate the role of precipitation recycling and advection in characterizing the 2011 and 2012 droughts in Texas and the Upper Midwest. We do this using the data from NOAA/NCEP's Climate Forecast System version 2 (CFSv2), which is a cuttingedge coupled atmosphere-ocean-land surface-sea ice modeling system applied at a high resolution on a global scale (Saha et al. 2014). In the second part, we investigate how well the CFSv2 forecasts capture different drought signals for the two events and the potential causes behind the discrepancies.

\section{Methods and data}

\section{a. Climate Forecast System forecast and analysis}

CFSv2 (Saha et al. 2014) is a high-resolution, coupled atmosphere-ocean-land surface-sea ice modeling system applied on a global scale. It has improved data assimilation and forecast model components as compared to its predecessor, that is, CFSv1 (Saha et al. 2006), and was made operational by NCEP in March 2011. The atmosphere, ocean, land surface, and sea ice models have 64,40 , 4 , and 3 levels, respectively. The initial conditions for the forecasting model are derived from a coupled reanalysis 
over 32 years (1979-2010), which ensures consistent and stable calibrations and skill estimates for seasonal and subseasonal predictions (Saha et al. 2014). Note that after NCEP discontinued the production of CFS Reanalysis (CFSR) in April 2011, CFSv2 Operational Analysis [Climate Data Assimilation System (CDAS)] was made available. Therefore, in this study, we combine both CFSR and CFSv2 operational analysis data to cover the entire analysis period (2010-13) and use the term "CFSv2 analysis" interchangeably to indicate either of these datasets.

In this study, we use six CFS variables, namely, precipitation, latent heat flux, precipitable water, soil moisture, specific humidity, zonal wind speed, and meridional wind speed. The first four variables are extracted from the surface flux files (Gaussian grid; T574 for analysis and T126 for forecasts), whereas the last three variables are from the atmospheric files with 3D pressure-level data (latitudelongitude grid; $0.5^{\circ}$ for analysis and $1.0^{\circ}$ for forecasts). The temporal resolution of the datasets is $6 \mathrm{~h}$. Analysis fields were available for all the variables except precipitation, for which the initial conditions ( 0 -h forecasts) were used (see Table S1 in the online supplemental material). CFSv2 forecast ensembles are based on different initialization times. Thus, at any given time, some ensemble members are newer while some are older based on when they were initialized. We analyze 20 CFSv2 ensemble forecasts during the time period of June-September (JJAS) for Texas in 2011 and the Upper Midwest in 2012. There are five different initialization days (11, 16, 21, 26, and 31 May) with four initialization times per day $(0,16,12$, and $18 \mathrm{~h})$. CFSv2 analysis variables are upscaled from $0.5^{\circ}$ to $1.0^{\circ}$ spatial resolution using barycentric linear interpolation with Delaunay triangulation to match the resolution of the forecasts.

\section{b. Precipitation recycling modeling}

Precipitation recycling is modeled in this study using the DRM, which is based on water vapor accounting in a $2 \mathrm{D}$ semi-Lagrangian framework. Compared to the other 2D models, the DRM relaxes the assumption of negligible atmospheric moisture storage, and thus, is applicable to the daily time scale. The model is based on the precipitable water budget and its changes due to precipitation, evaporation, and the convergence of the vertically integrated moisture flux. As such, the model has been useful for studying first-order water vapor transport at the continental scale.

According to the DRM, the fraction of atmospheric moisture collected by an air column along its trajectory while passing through two adjacent regions (from time $t_{2}$ to $t_{1}$ in region 2 and from $t_{1}$ to $t_{0}$ in region 1 , where $t_{0}$ represents the present time, $t_{1}$ is previous to $t_{0}$, and $t_{2}$ is previous to $t_{1}$ ) is given by

$$
\begin{aligned}
R(x, y, t)= & 1-\exp \left[-\int_{t_{2}}^{t_{0}} \frac{E(x, y, t)}{W(x, y, t)} d t\right] \\
= & \alpha_{0}(x, y, t) R_{1}(x, y, t) \\
& +\alpha_{0}(x, y, t) \alpha_{1}(x, y, t) R_{2}(x, y, t),
\end{aligned}
$$

where $E$ is the amount of evaporation, $W$ is the amount of precipitable water, $R_{1}$ and $R_{2}$ are related to the local collections of moisture from region 1 (local source and sink) and region 2 (external source); $\alpha_{1}$ accounts for the fraction of moisture produced in region 2 that is not precipitated in region 1 . In addition $\alpha_{1}(x, y, t)=1-R_{1}(x, y, t)$. The term $\alpha_{0}$ is defined as equal to 1 , and it is introduced in order to extend the notation of the indices in Eqs. (1) and (2). More details about the $R$ and $\alpha$ terms are presented in Martinez and Dominguez (2014). According to the DRM, the fraction of moisture collected by an air column from a given region along the portion of trajectory $\lambda$, which finally reaches a target region at $t_{0}$, is given by

$$
c_{\lambda}(x, y, t)=\left[\prod_{j=0}^{\lambda-1} \alpha_{j}(x, y, t)\right] R_{\lambda}(x, y, t) .
$$

It is possible to have multiple trajectories within a single region, in which case, the net contribution of any region $A_{k}$ can be expressed as the sum of the contributions from the individual trajectories within that region:

$$
a_{k}(x, y, t)=\sum_{\lambda \in A_{k}} c_{\lambda}(x, y, t),
$$

where $a_{k}($ not $\alpha$ ) is the fraction of moisture on each grid cell within the domain, which originated as evaporation from region $A_{k}$. So, the total fraction of atmospheric moisture collected across $N_{A}$ regions can be written as

$$
R(x, y, t)=\sum_{k=1}^{N_{A}} a_{k}(x, y, t) .
$$

Following are some key points that need to be taken into account while using the DRM:

1) The recycling ratio within a grid cell can be modeled either in terms of precipitable water or precipitation. In the DRM, the recycling ratio at any grid cell is the same for precipitable water and precipitation, following the assumption of a well-mixed atmosphere. However, this does not hold true when regional averages are calculated. This is due to the fact that not all of the available precipitable water ends up as precipitation. Therefore, the spatial structures of these two variables are also different. In this study, we focus on regional averages of both the variables to get a complete picture of the moisture distribution. 
2) The DRM does not account for all the actual precipitable water or precipitation within a given region because some of this moisture can originate outside the domain under consideration. This is not a critical issue for regions that are in the middle of the domain since most of the moisture there comes from around the vicinity, which is already included in the domain. However, the regions near the boundaries of the main domain show much less moisture accounting as a result of not factoring in the sources outside the domain (see Fig. S1).

3) The two-dimensional approximation of the DRM has been a subject of debate (Van Der Ent and Savenije 2013; Goessling and Reick 2013), particularly in regions of strong shear. However, the model has proven to work well for larger domains (e.g., La Plata River basin in South America), without significant wind shear (Dominguez et al. 2006; Martinez and Dominguez 2014).

4) The DRM requires effective $2 \mathrm{D}$ zonal and meridional wind as inputs to calculate recycling. In the analytical solution that leads to the DRM, these winds correspond to the vertically integrated moisture flux vectors, divided by the precipitable water. However, we find that this approach tends to ignore the effects of topographic barriers and overestimates moisture transport in regions where lower level atmospheric circulation acts as a dominant moisture transport mechanism. Therefore, we implement an alternative approach, where the $2 \mathrm{D}$ effective wind vector is calculated by taking the weighted average of the wind vectors at 1000,850 , and $700 \mathrm{hPa}$ pressure levels, following the method developed by Wimmers and Velden (2011). This method was originally applied to interpolate precipitable water fields over the ocean, using wind fields from an atmospheric model (Wimmers and Velden 2011). In our case, the use of the same method, even over the land, for obtaining effective 2D wind fields resulted in a more realistic spatial distribution of atmospheric moisture transport patterns as compared to the vertical integration approach. Additionally, this version of the DRM was able to account for more moisture for each region (see Fig. S2).

\section{c. Study regions}

The first step in running the DRM involves the delineation of the study regions. Figure 1 shows the 32 regions constructed in this study in such a manner that they subdivide the continent into smaller regions (especially at the core of the continent), while the regions over the oceans have larger areas. This is useful to better capture the more complex moisture circulation patterns over the land surface. The model provides recycling and advection components of precipitation in each of these 32 regions. In this study, the regions of interest (sinks) are region 14 (R14) and region 8 (R08), which we refer to as "Texas" and "Upper Midwest," respectively.

\section{d. Workflow}

To study the role of precipitation recycling, we run the DRM with the CFSv2 analysis data for three consecutive years, with the drought year placed in the middle. Thus, for Texas, we run the model from 2010 to 2012 (drought year 2011) and for the Upper Midwest from 2011 to 2013 (drought year 2012). For CFSv2 forecasts, we specifically focus on the respective drought years (2011 for Texas and 2012 for the Upper Midwest). The study involves 44 different simulations using the DRM model (four year-long simulations with CFSv2 analysis for 2010-13 and 20 summer runs with CFSv2 forecasts separately for 2011 and 2012). All the variables except for zonal and meridional winds are aggregated to the daily level. Wind components are used at 6-hourly time step to capture the diurnal variability. The spatial resolution is set at $1.0^{\circ}$ for all the analyses carried out in this study. The CFSv2 analysis data from May are used as the spinup for the CFSv2 summer (JJAS) forecasts. Local moisture recycling, as well as moisture advection, is calculated from the model runs for each day.

\section{Results and discussion}

In this section, we present the results from the diagnostic study of the two drought events as well as the comparison of CFSv2 analysis and forecasts. Drought years in this study are identified as having anomalously low precipitation/evapotranspiration/soil moisture or a combination thereof, in comparison to the preceding and following years. Thus, for Texas, we consider 2011 as the drought year and 2010 and 2012 as the nondrought years. Likewise, in the Upper Midwest, 2012 is considered to be the drought year and 2011 and 2013 as the nondrought years.

\section{a. CFSv2 analysis precipitation}

We use the CFSv2 analysis data both for drought diagnostics as well as forecast comparison. Figure 2 compares summer (JJAS) precipitation total from six different sources: CFSv2 analysis or CFSR, ModernEra Retrospective Analysis for Research and Applications (MERRA; Rienecker et al. 2011), the European Centre for Medium-Range Weather Forecasts (ECMWF) interim reanalysis (ERA-Interim; Dee et al. 2011), the Japanese 55-year Reanalysis (JRA-55; Kobayashi et al. 2015), Global Precipitation Climatology Centre (GPCC; Ziese et al. 2014) gridded observations, and 


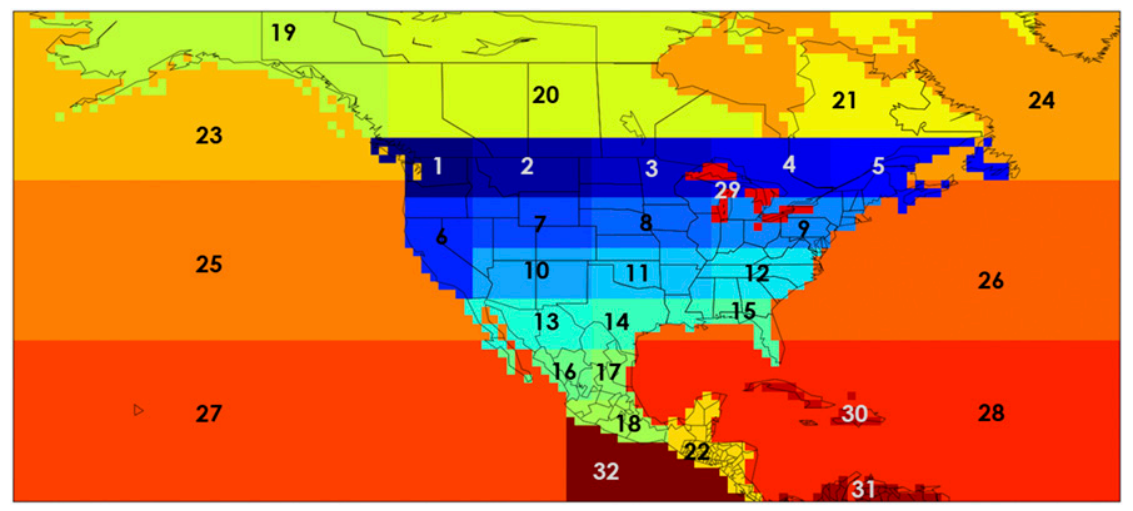

FIG. 1. The 32 regions designed in this study for running the DRM. Note that in the way the regions are defined in this study, they do not completely correspond to the state boundaries. We call region 14 (R14) the "Texas Region," which includes parts of Texas, Louisiana, Mississippi, and Mexico. The "Upper Midwest Region" is represented by region 8 (R08), which includes parts of Minnesota, South Dakota, Wisconsin, Nebraska, Kansas, Iowa, Missouri, and Illinois.

Parameter-Elevation Regressions on Independent Slopes Model (PRISM; Daly et al. 1994) gridded observations. JRA-55 precipitation is in general higher for both regions as compared to the other products. CFSv2 analysis shows lower precipitation as compared to the other products (mainly in the Upper Midwest) until around 2004, after which it lies well within the interproduct spread. Clearly, all the precipitation products show the lowest amount of summer precipitation in 2011 for Texas and 2012 for the Upper Midwest. The spatial precipitation field of CFSv2 analysis also compares well with the precipitation from the North American Land Data Assimilation System phase 2 (NLDAS-2; Mitchell 2004) and the recently developed Multi-Source Weighted-Ensemble Precipitation (MSWEP; Beck et al. 2017, 2019). See Fig. S3 for monthly comparisons of the three products.

\section{b. Analysis of hydrometeorological variables}

Figure 3 shows the cumulative plots of precipitation, precipitable water, evapotranspiration, and soil moisture from the CFSv2 analysis for Texas and the Upper Midwest during 2010-12 and 2011-13, respectively. Note that although they are storage variables, we plotted the cumulative values of precipitable water as well as soil moisture just to identify the differences more clearly. The time series plots of these variables (without accumulations) are provided in Fig. S4. In both regions, drought has been reflected in the anomalously low values of all four variables, with precipitation and evapotranspiration showing the strongest signals.

As reflected in the time series of precipitation and evapotranspiration (Fig. S4), in Texas, the month of April happens to be the onset of the drought event in 2011. The entire summer season (JJAS) looks dry except for some small rainfall events in July and September. June and August appear to be the driest months. Precipitation signal is strongly reflected in evapotranspiration and soil moisture. Drought signal is reflected in the soil moisture as early as February for this region. The cumulative precipitation and precipitable water plots of Fig. 3 for Texas show a decrease in both variables, and so the drought was more likely related to moisture transport. Internal atmospheric variability causing mean flow moisture divergence and drying (Seager et al. 2014) might have played a key role in determining the moisture transport pattern during this period. The drought in Texas was initiated in the fall of 2010 (Seager et al. 2014) but became much stronger during the following year (see Fig. 2).

In the Upper Midwest, drought did not emerge until May/June, and the duration of the event was also shorter as compared to the Texas drought. This agrees with the findings of Hoerling et al. (2014), who characterized the event as a "flash drought." As can be seen in Fig. S4, the difference between drought and nondrought year evapotranspiration is largest during the months of July and August. Soil moisture shows similar characteristics; however, the drought signal is reflected much earlier (April). Strong drought signal is also seen in precipitation during July and August. Some amount of precipitation occurred during the end of June and August, but the overall precipitation was low as compared to the other years. Precipitable water shows no or little anomaly, although there was a significant decrease in precipitation (Fig. 3). This suggests that the negative precipitation anomaly was largely influenced by the absence of precipitationgenerating mechanisms, which is in line with the findings of Hoerling et al. (2014), who, along with the reduced Gulf of Mexico moisture transport, identified reduced cyclone and frontal activity and inhibition of summer convection as the key reasons behind the drought in the central Great Plains. During 2012 in the Upper Midwest, precipitation 


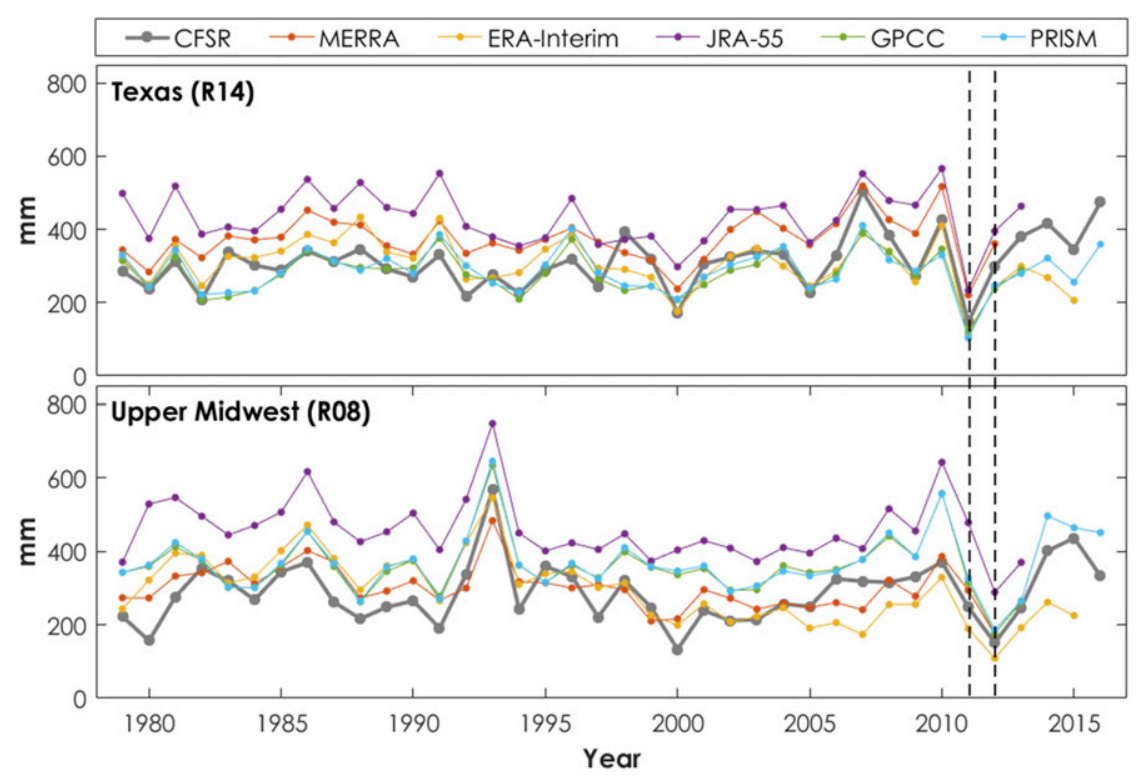

FIG. 2. Summer (JJAS) precipitation total from CFSv2 analysis (CFSR), MERRA, ERAInterim, JRA-55, GPCC, and PRISM. Data from Climate Reanalyzer (http://cci-reanalyzer. org), Climate Change Institute, University of Maine.

was reduced early, although evapotranspiration did not drop until late June. Soil moisture was likely a contributor to evapotranspiration until this point, beyond which it was too low for sustaining evapotranspiration. In early April, soil moisture started decreasing and, unlike the nondrought years, did not recover due to low precipitation. Evapotranspiration reached the minimum value by the end of June and the lowest values persisted until the end of summer, when the drought was alleviated by increased precipitation.

\section{c. Analysis of recycling and advection}

Figure 4 shows the moisture contributions from the different regions defined in Fig. 1 to precipitation in Texas and the Upper Midwest as calculated with the DRM (similar figure with precipitable water is given in Fig. S5). The patterns of relative and absolute advection and recycling were similar for the most part in both of these regions, with a few exceptions (e.g., advection from R28 to Texas). Although recycling decreased during the respective drought years, the relative contributions of all the sources were similar for all the years in both regions. A similar figure created using precipitable water instead of precipitation, which shows similar results, is shown in Fig. S5.

In Texas, the primary moisture contribution was from the tropical Atlantic (R28), which is consistent with the seasonal location of the Bermuda high pressure system, affecting moisture flows into the southern United States (Wang et al. 2010; Kam et al. 2014). The next big sources of moisture for Texas were the midlatitude Atlantic (R26) and recycling (R14). Several regions contributed moisture to the Upper Midwest, including recycling, neighboring regions [including parts of the northern United States (R03) and the Southwest (R10)], southern Canada (R20), and the tropical Atlantic (R28). Clearly, recycling and terrestrial evapotranspiration are important sources of moisture for the Upper Midwest, which is reasonable given the location of the region (surrounded by landmass as opposed to oceans).

During the drought, the amount of precipitation from recycling decreased in proportion (\%) in the Upper Midwest (Fig. 4), and to a lesser extent in Texas. While it may appear intuitive, it is not necessarily trivial, since moisture recycling expressed as a fraction of total precipitation has been shown to be sometimes negatively correlated to precipitation (Dominguez and Kumar 2008). In other words, in the Upper Midwest, when total precipitation decreases, moisture recycling can actually be high. This is because advection is the main driver of (high) precipitation, and when advection becomes weaker, the overall precipitation amount decreases. Evapotranspiration from local sources (i.e., recycling) then becomes important to sustain low precipitation. Furthermore, recycling ratios change as a function of the area of the region of interest (Dominguez et al. 2006; Dirmeyer and Brubaker 2007). In our case, both recycling and advection are seen to decrease during the drought years both in terms of recycling ratio (relative) and recycled amount (absolute).

Figure 5 shows spatially the advected and recycled precipitation components $(\mathrm{mm})$ during the summer 

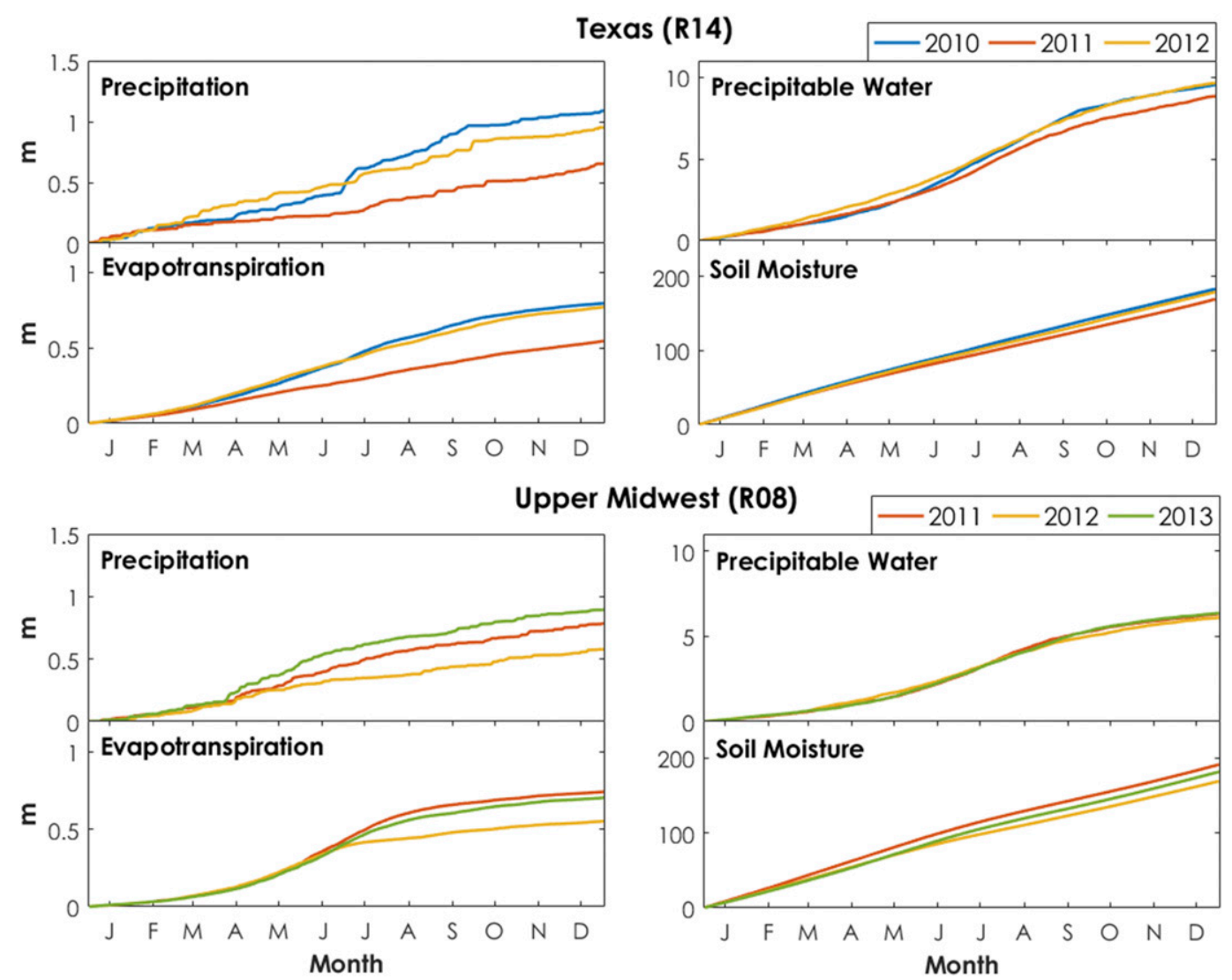

FIG. 3. Cumulative plots of precipitation, precipitable water, evapotranspiration, and soil moisture in Texas during 2010-12 and the Upper Midwest during 2011-13 in the CFSv2 analysis.

(JJAS) of the three consecutive years in both Texas and the Upper Midwest regions (a similar figure with precipitable water is shown in Fig. S6). The green box represents the area of interest, for which the advected and recycled components are calculated. In Texas, the contributions from the midlatitude Atlantic (R26) and recycling (R14) were reduced during the drought year. Small contributions from the Pacific that were seen in 2010 also disappeared in the following years. The postdrought year showed similar spatial patterns as the drought year but with larger magnitudes. In the Upper Midwest, contributions from the tropical Atlantic (R28), midlatitude Pacific (R25), and recycling were reduced during the 2012 summer. Contrary to the Texas drought, which involved primarily reduced advection from oceanic sources and reduced recycling, several land regions (e.g., the western United States) also played a crucial role in characterizing the Upper Midwest drought.

Figure 6 shows the temporal patterns of local recycling and advection from the corresponding significant sources (different for Texas and the Upper Midwest) during the summer of 2010-13. For clarity, Fig. 6 shows cumulative amounts; the absolute time series plots are shown in Fig. S7. Precipitation recycling was noticeably lower than usual in both regions, especially during the summer of the corresponding drought years. In Texas, during the drought year (2011), precipitation recycling started decreasing from mid-April and remained low all throughout the summer. In the Upper Midwest, recycling was low throughout the drought year (2012), except for some peaks in December, when the drought had already weakened.

For Texas, the most significant source of precipitation was advection from tropical and midlatitude Atlantic (R26 and R28), the contribution of which was significantly low since the beginning of the drought year (2011) until late summer. The high advection during the end of summer alleviated the drought event during that year. The next significant sources of precipitation were local recycling and advection from the contiguous United States (CONUS; excluding R14). While recycling, as well as advection from the Atlantic, reduced significantly during the drought year, CONUS advection did not alter much. Thus, it could be argued that precipitation from terrestrial sources did not significantly influence the drought event. In fact, this precipitation more 

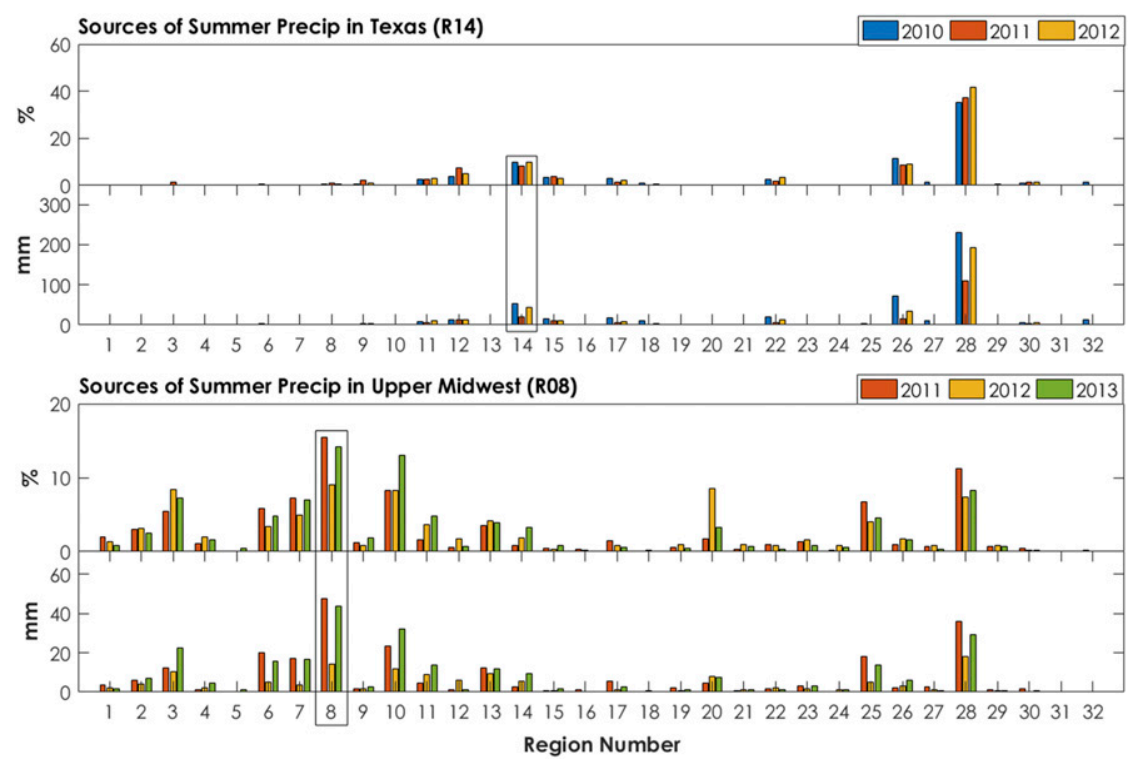

FIG. 4. Advection from different source regions (see Fig. 1) to Texas and the Upper Midwest derived from the CFSv2 analysis, expressed both as fractions of annual precipitation (\%; top graph in each panel) and absolute amounts ( $\mathrm{mm}$; bottom graph in each panel). Values for Texas and the Upper Midwest, indicated by the black boxes, correspond to the recycling ratio (\%) and recycled precipitation $(\mathrm{mm})$. Note that the sum of the percentages of all regions in any given year is not necessarily $100 \%$, since the DRM does not account for all the moisture as a result of losses across the boundaries.

likely played a role in alleviating the drought intensity to some extent, which was characterized primarily by long-range moisture transport (from oceanic sources) and recycling. Precipitation from terrestrial origin collected during the late winter (January-February) was nearly enough to sustain accumulated terrestrial precipitation to similar levels observed in nondrought years, with interesting contributions from the Southwest (R10) and Upper Midwest (R08). However, precipitation recycling in Texas and advected precipitation from the Atlantic were lower during the drought year and dominated the precipitation negative anomalies over the region. Advection from the northern and southwestern United States (R03, R08, and R10) was seen to slightly increase during the drought year; however, the magnitude was much smaller as compared to the dominant moisture sources. The generalized decrease in moisture transport from different regions is consistent with the general decrease in convergence reported by Seager et al. (2014) for Texas. However, despite the overall decrease, even since the fall of 2010 (Seager et al. 2014), we found that terrestrial sources contributed more precipitation to Texas during the winter prior to the summer drought compared with the same contribution during the nondrought years. Specifically, our estimates suggest a larger contribution from the CONUS during January-February, which kept the accumulated contributed precipitation from the CONUS during 2011 higher than in 2010 and 2012. However, this was not enough to keep Texas away from a drought. This highlights the importance of upwind land regions for precipitation and suggests that a weaker role of these sources could have made the summer drought even worse.

The main contributors of precipitation in the Upper Midwest were recycling, tropical Atlantic, midlatitude Pacific, and terrestrial sources. Unlike Texas, the contribution from the terrestrial sources also decreased during the drought year in this case (can be seen in Figs. 4-6). Recycling started decreasing as early as March but the advection from the CONUS (excluding R08) started decreasing in June. As a result, the onset of drought, in this case, was late compared to Texas (see Fig. 3). During 2012, advection from the midlatitude Pacific was significant during the spring as well as the preceding (2011) winter. However, it decreased during the summer of 2012. The contribution from the tropical Atlantic was low throughout the spring and summer of 2012, but it increased during the end of summer. Hoerling et al. (2014) reported a reduction in precipitation related to environments less favorable to precipitation, including high pressure between May and August. We also found a general decrease in the precipitation contributed from different regions to the Upper Midwest, especially during the summer of 2012. 

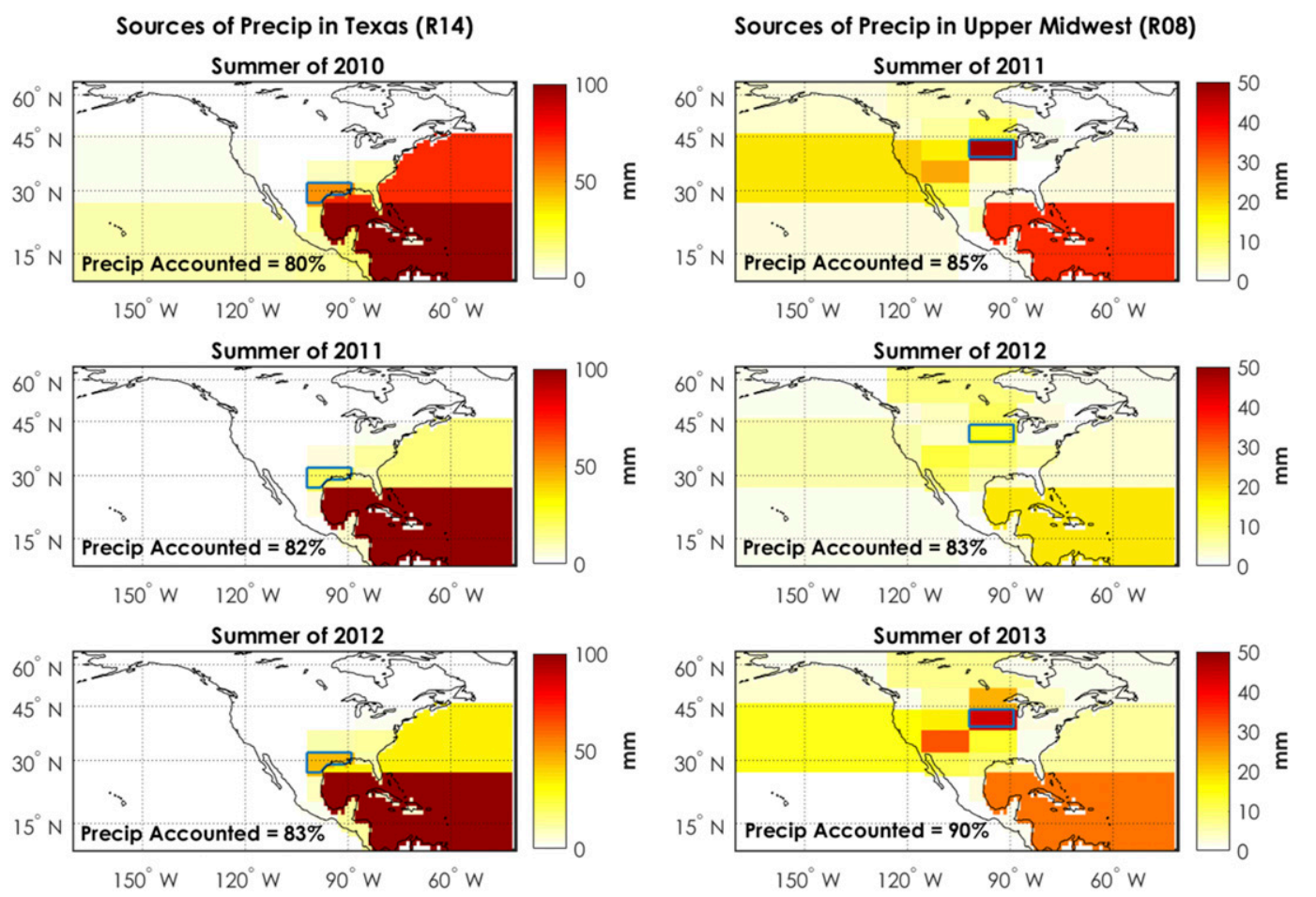

FIG. 5. Spatial patterns of recycled and advected summer precipitation over Texas and the Upper Midwest from CFSv2 analysis (note the difference in units for the two regions).

However, we also note that contributions from the midlatitude Pacific (likely related to synoptic activity) were equal or larger during 2012 compared to 2011 and 2013 between January and May and accumulated precipitation from the CONUS shows the largest decline after June, in contrast to the sharp decrease in contributions from recycling and tropical Atlantic since April.

\section{d. Comparison of forecasts and analysis}

In this section, we compare the CFSv2 analysis and forecast data to see how well the forecasts were able to capture different drought signals. In particular, we compare the hydrometeorological variables (precipitation, evapotranspiration, precipitable water, and soil moisture) as well as the recycled and advected precipitation components for both products (Figs. 7, 8).

For Texas, the ensemble mean precipitation from the forecasts closely follows the analysis. In general, the more recent forecasts (darker gray) tend to underestimate precipitation, while the earlier forecasts (light gray) tend to overestimate precipitation, while compared against the precipitation from the analysis. On the other hand, in the Upper Midwest, all the forecasts significantly overestimate precipitation. Evapotranspiration is overestimated in both regions, but the differences are more striking for the Upper Midwest, where significant overestimation is evident during July and
August (see Fig. S8). This could be related to the lack of details/processes in the land surface model (Noah) within the CFS system, which results in unrestricted transpiration, even in dry conditions. The problem exacerbates during summertime as transpiration is increased to account for the temperature bias. The mean precipitable water is similar for both forecasts and analysis in Texas, whereas in the Upper Midwest, the forecasts show overestimation, which is consistent with the overestimation of precipitation. The temporal profiles of soil moisture from the analysis and forecasts match to some extent for the Upper Midwest. However, in Texas, almost all the ensemble members underestimate soil moisture. In Texas, for all four variables, the more recent forecast ensemble members (darker curves) in general tend to be lower than the respective ensemble means, while in the Upper Midwest, the newer ensemble members match better the ensemble mean. In all cases, the variability of the ensemble members decreases with the initialization time, that is, less variability in the newer ensembles and vice versa.

As can be seen in Fig. 8, the recycled and advected precipitation components from the analysis data are well captured by the forecast ensemble during the summer of Texas. However, in the Upper Midwest, both of these components are significantly overestimated by the forecasts during the same period, following the similar 

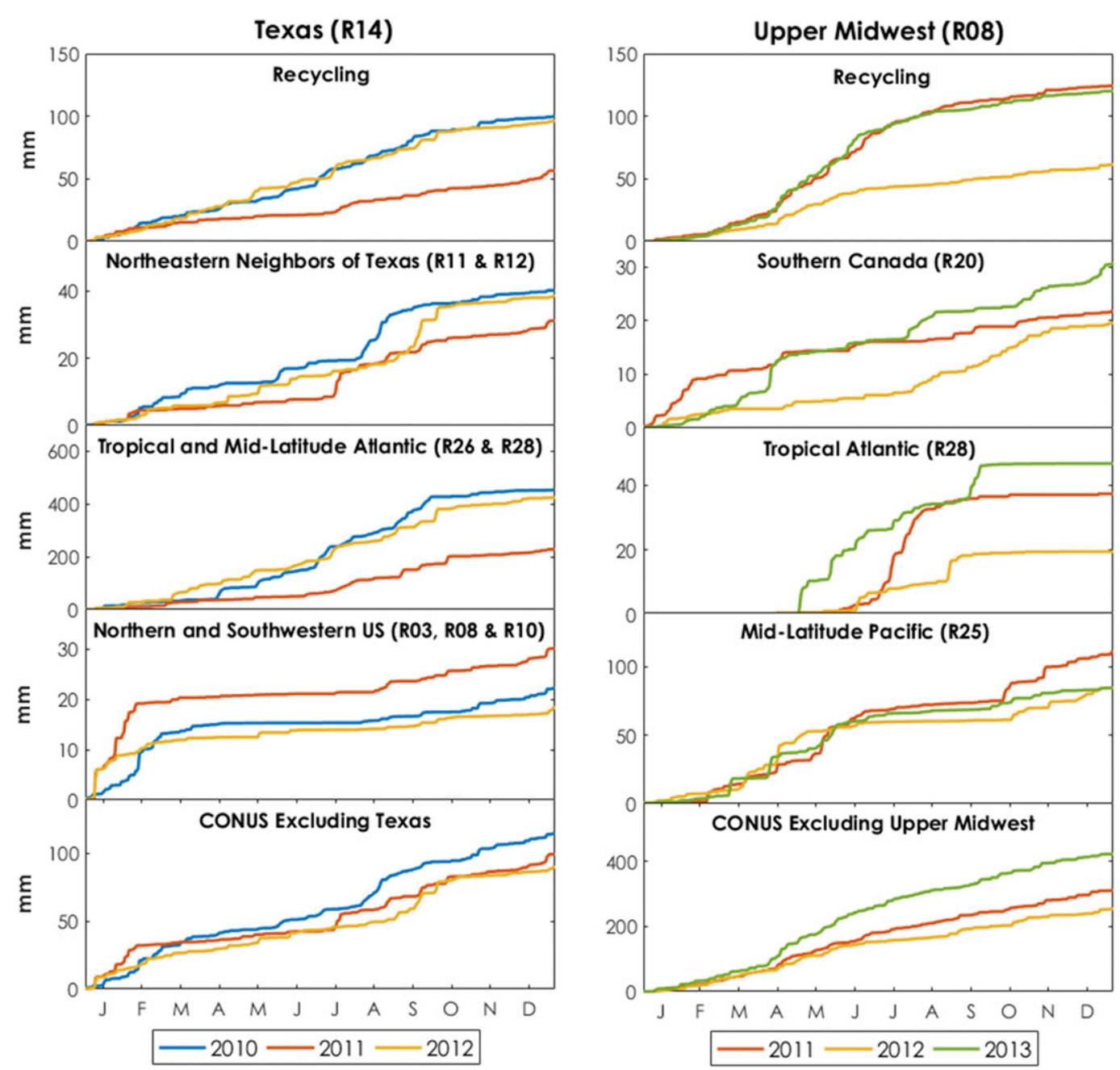

FIG. 6. Cumulative plots of recycled and advected precipitation over Texas and the Upper Midwest from the CFSv2 analysis (note the difference in the scales for the two regions).

behavior of total precipitation (Fig. 7). Similar to what is seen in Fig. 7, the newer ensemble members for both advected and recycled precipitation in general stay below the respective ensemble means in Texas, while in the Upper Midwest, the newer members show better match with the ensemble means. The variability among the ensemble members also decreases with the initialization time (less variability in newer members).

To get a better idea about the partitioning of total precipitation into recycled and advected components in both analysis and forecasts, we calculated some diagnostic ratios from the DRM results, as shown in Table 1. Note that the ensemble mean is used for calculating the ratios for the forecasts. During the drought year (2011) summer in Texas, the advected precipitation was about 9.21 times higher than the recycled precipitation for the analysis, while the same ratio was 7.77 times higher for the forecasts. In the Upper Midwest, during the drought year (2012) summer, these ratios were about 8.45 and 3.76 , respectively. The low values of the ratio in case of forecasts are attributed to larger local evapotranspiration produced by the forecasts (Fig. 8), which is more striking in the Upper Midwest. In Texas, the ratio of advected analysis and advected forecasts is 1.14 and the ratio of recycled analysis and recycled forecasts is 0.96 , which indicate that the forecasts and analysis are in good agreement. In contrast, for the Upper Midwest, the same are 0.45 and 0.20 , respectively. These large differences are also evident from Fig. 8. In this case, both advected and recycled components are overestimated by the forecasts, but the recycled one relatively more so. The ratio of advected analysis and recycled analysis is higher for both regions during the drought years (compared to the preceding and following years), and these differences are also more striking in the Upper Midwest. 
Texas (R14) during 2011 Summer
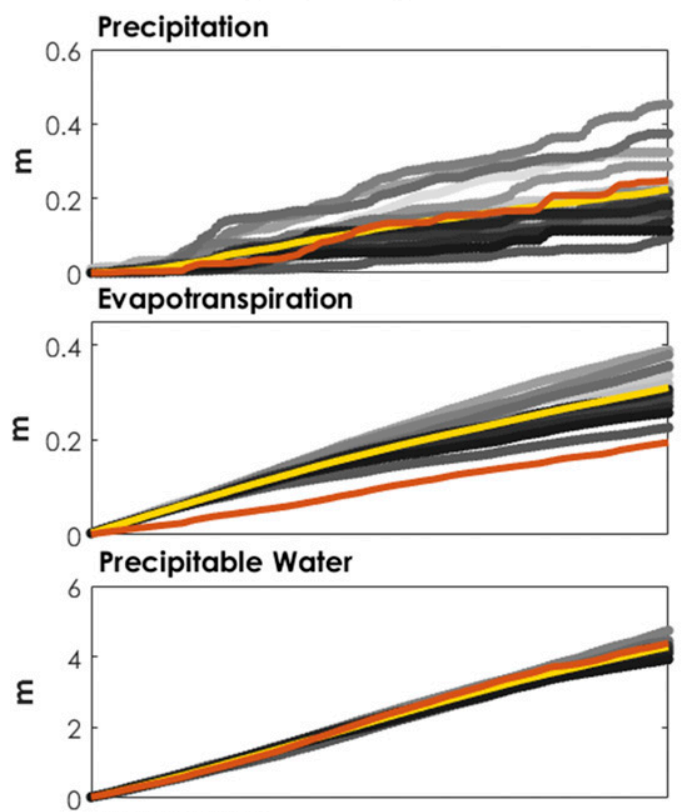

Soil Moisture

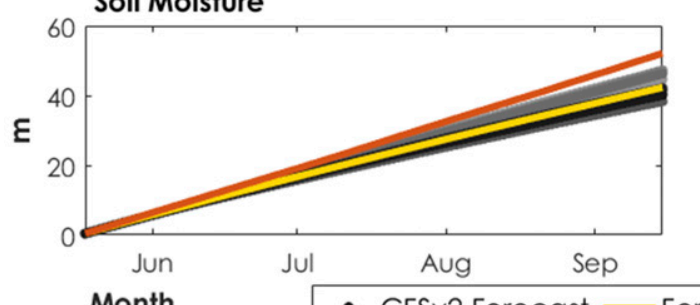

Upper Midwest (R08) during 2012 Summer
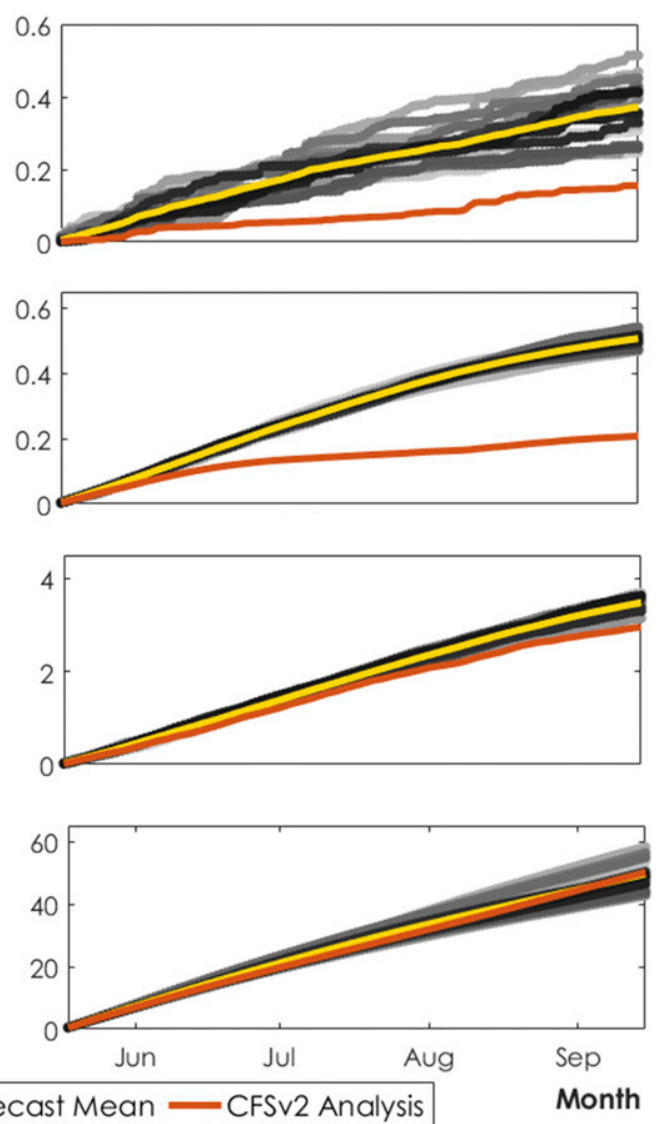

FIG. 7. Comparison of cumulative precipitation, evapotranspiration, precipitable water, and soil moisture from CFSv2 analysis and forecasts. Darker gray dots represent newer forecast ensemble members based on the time of initialization.

This implies that although precipitation was low during the drought years (Fig. 3), the relative fraction of advected precipitation increased as compared to recycled precipitation.

The next set of diagnostic ratios was calculated to compare the advection contributions from the oceanic and terrestrial sources during the drought and normal (preceding and following) years. In general, the ratios are smaller for the preceding year in both regions, implying that the following year was relatively drier as compared to the preceding year. In Texas, the fractional decrease in contributions from the tropical and midlatitude Atlantic was larger as compared to the land sources ( 0.41 vs 0.79 for the preceding year and 0.55 vs 0.92 for the following year), which suggests the partial shutdown of long-range moisture sources. In such conditions, land sources can actually assuage drought intensity, even with negative anomalies. In the Upper Midwest, the fractional decrease in contributions from the tropical Atlantic was higher as compared to the land sources ( 0.50 vs 0.66 ), however, this behavior reversed for the following year ( $0.64 \mathrm{vs} 0.48$ ). The more significant oceanic moisture source in the Upper Midwest was the midlatitude Pacific, the contributions of which decreased more during the drought year as compared to the land sources, and this pattern was similar for both the preceding and following years $(0.29$ vs 0.66 in the preceding year and 0.38 vs 0.48 in the following year), suggesting the partial shutdown of long-range moisture transport, similar to Texas.

We also studied if the skill of the forecasts measured in terms on normalized mean bias (NMB) and Pearson's linear correlation coefficient $R$ improves with the time of initialization (see Fig. S10). NMB tends to decrease with the initialization time (more recent forecasts are associated with lower NMB and vice versa) for precipitation in Texas. However, in the Upper Midwest, there is no clear pattern of improvement. The estimates 


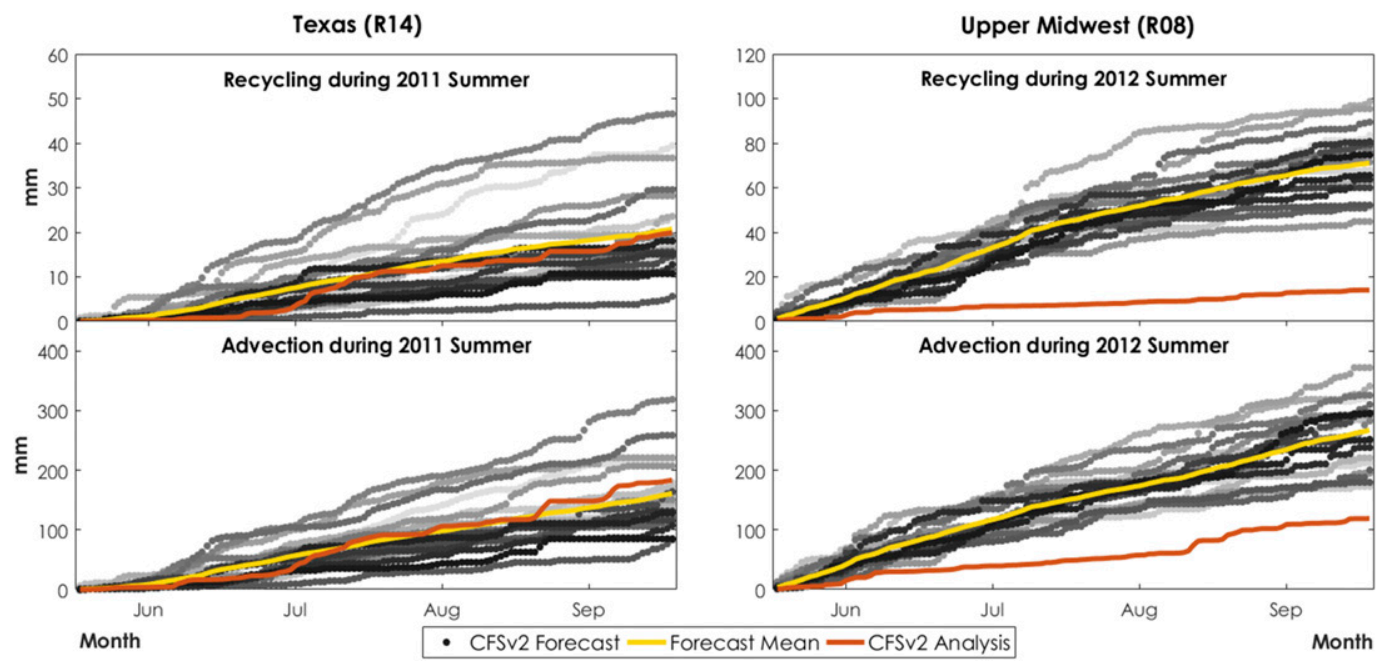

FIG. 8. Comparison of advected and recycled precipitation (cumulative) from CFSv2 forecasts and analysis. Darker gray dots represent newer ensemble members. Note the differences in $y$-axis scale between panels.

of NMB stabilize with the initialization time in both cases. Correlation coefficient $R$ does not show any noticeable increasing or decreasing trend, although the most recent forecasts (initialized at 1800 UTC 31 May) correspond to the highest value of the metric for Texas precipitation. NMB for evapotranspiration improves in Texas but does not change much in the Upper Midwest. For evapotranspiration, $R$ has a slightly decreasing trend with the initialization time in Texas and a slightly increasing trend in the Upper Midwest. NMB of precipitable water and soil moisture does not change much in both regions. The $R$ value tends to increase with the initialization time for precipitable water and to decrease with soil moisture in Texas. Note that we only studied a small subset of the total forecast ensemble in this case.
While this provides some overall idea about the potential skill of the forecasts, the analysis presented here, by no means, can or is meant to substitute a rigorous assessment of forecasting skill based on the initialization and lead times of forecasts.

\section{e. Implications of the results}

The two drought events considered in this study differed in their underlying mechanisms, which also likely contributed to the differences in the performance of the forecasts. Although moisture transport from the oceanic sources was reduced in both cases, the Upper Midwest had more prominent contributions from the land surface. Both the advected and recycled components of precipitation were overestimated in the Upper Midwest.

TABLE 1. Diagnostic ratios calculated for the summer (JJAS) from DRM results.

\begin{tabular}{llcc}
\hline \hline & \multicolumn{1}{c}{ Ratios } & Texas & Upper Midwest \\
\hline \multirow{2}{*}{ Drought year } & Advection and recycling contributions & & 9.45 \\
& Advected analysis/recycled analysis & 7.77 & 3.76 \\
& Advected forecasts/recycled forecasts & 1.14 & 0.45 \\
& Advected analysis/advected forecasts & 0.96 & 0.20 \\
Preceding year & Recycled analysis/recycled forecasts & 8.31 & 3.99 \\
Following year & Advected analysis/recycled analysis & 6.90 & 4.88 \\
& Advected analysis/recycled analysis & & 0.38 \\
Drought year and preceding year & Oceanic and terrestrial contributions & 0.79 & 0.31 \\
& Recycling drought/recycling normal & - & 0.56 \\
Drought year and following year & CONUS drought/CONUS normal & 0.45 & 0.29 \\
& Atlantic drought/Atlantic normal & 0.92 & 0.32 \\
& Pacific drought/Pacific normal & 0.55 & 0.48 \\
& Recycling drought/recycling normal & - & 0.38 \\
\hline
\end{tabular}


The inconsistencies in the forecast precipitation could be attributed to several factors, including the representation of atmospheric processes (e.g., microphysics and cumulus parameterizations), surface processes (land surface model), and land-atmosphere interactions (landatmosphere coupling within the model). For example, Jiang et al. (2009) showed that adding an interactive canopy model and a simple groundwater model to Noah results in improved summer precipitation simulation in the central United States. In another example, Anyah et al. (2008), using the land surface model Land-EcosystemAtmosphere Feedback (LEAF) with groundwater dynamics (LEAF-Hydro), found that a simple groundwater scheme was associated with more soil moisture and precipitation over parts of the Upper Midwest and Texas during September. A fully coupled groundwateratmosphere module can significantly improve the representations of water partitioning within the modeling system. The overestimation of forecast advection in the atmospheric component of the CFS could be due to the errors in the forecasting of atmospheric circulation patterns or disturbances several weeks in advance, bringing, for example, more moisture from the tropical Atlantic compared to the atmospheric analysis.

Evapotranspiration was overestimated by the forecasts in both cases, but more so in the Upper Midwest. This could be attributed to the unrestricted evapotranspiration in the land surface model component within the CFSv2 system. It could be that the model keeps evaporating from the deep soil to meet the warm bias, resulting in excessive evapotranspiration over the summer period. The model might have reached deeper soil layers in the Upper Midwest, thereby causing larger overestimation of evapotranspiration in this region. Note that in the Noah model, the root zone for all types of vegetation is the entire soil column, which can lead to overestimation of transpiration by vegetation from the uppermost soil layers (grass, crops, etc.). The lack of dynamic vegetation could also play a role in continuing transpiration even in dry conditions because of the use of a vegetation phenology-based climatology in the model. Noah-MP includes a simple module for representing dynamic vegetation, which in principle could help to improve the simulation of evapotranspiration. However, this potential improvement is not straightforward. For example, a version of Noah-MP with dynamic vegetation still produced more evapotranspiration over most of the CONUS compared to the baseline model Noah (Yang et al. 2011).

Soil moisture was underestimated in Texas, whereas in the Upper Midwest, the first half of summer showed overestimation and the other half showed underestimation. The underestimation of soil moisture in Texas could be a result of an increased forecast of evapotranspiration in the region. Several other factors can also affect the soil moisture forecasts, which is already difficult to simulate in the land surface models (Koster et al. 2009; Dirmeyer et al. 2018). The observations of this variable are scarce and associated with large uncertainties which make benchmarking and improvement of land surface models more challenging (Dirmeyer et al. 2016). Comprehensive studies in this direction (e.g., Dirmeyer et al. 2016, 2018) have found that global land surface models, like Noah in the CFS, have biases not only on their mean values of soil moisture but also on their seasonality, interannual variability (standard deviation), and memory (decorrelation time). The authors of those studies suggest that only longer time series of soil moisture measurements, both from in situ and satellite estimates, would help to improve the simulations of characteristics like interannual variability and memory traits of soil moisture. These aspects could be important in the simulation of variations at the seasonal and longer time scales. In terms of model components, this variability involves the feedbacks and interactions between land surface fluxes, soil moisture, shallow groundwater, runoff, and seasonal snowpack. We note that validation and benchmarking of land surface models for the simulation and forecast of climate extremes like droughts can be even more challenging, given the rarity and extreme characteristics of these events.

\section{Summary and conclusions}

In this study, we investigate the 2011 drought in Texas and 2012 drought in the Upper Midwest by analyzing several hydrometeorological variables from CFSv2 analysis data and forecasts. We use the DRM to study the recycled and advected components of precipitation separately during these two events. We compare a subset of CFSv2 forecasts against the analysis data within the context of the two drought events to see how well the forecasts captured different drought characteristics. Drought generally involves negative anomalies in several hydrometeorological variables as the signal travels through the hydrologic cycle. Therefore, in order to study the drought characteristics, we looked at four different variables, namely, precipitation, evapotranspiration, precipitable water, and soil moisture, for the corresponding drought years, as well as one preceding and one following year.

CFSv2 analysis was an appropriate choice as the reference dataset since it compared well with datasets from other sources, both for spatial and temporal precipitation fields. The drought was evident in the 
anomalously low values of all four variables in both regions, while the strongest signals were seen in precipitation and evapotranspiration. The Texas drought was dominated by the changes in moisture transport, where the internal atmospheric variability also played a crucial role (Seager et al. 2014). In the Upper Midwest, a lack of precipitation-generating mechanisms contributed to the drought event, as also suggested by Hoerling et al. (2014). Drought in the Upper Midwest was short, emerging in May/June of 2012, whereas in Texas, it started as early as April of 2011. June and August appeared to be the driest months in Texas, while in the Upper Midwest, July and August were the driest, and in both cases, drought was alleviated by the end of August. The significant sources of moisture in Texas are the tropical and midlatitude Atlantic, recycling, and the CONUS, whereas, in the Upper Midwest, the midlatitude Pacific, tropical Atlantic, CONUS, and recycling are the substantial contributors. The Texas drought was caused primarily because of the reduced advection from oceanic sources as well as reduced recycling, while in the Upper Midwest, several land regions, especially in the western United States, also influenced the drought along with the oceanic sources. The contributions from all the sources were low during the corresponding drought years. In both regions, partial shutdown of long-range moisture transport was evident, and in such conditions, land sources can contribute to alleviating drought intensity, even with negative anomalies. It should be noted that the recycling component can increase during dry conditions, indicating that low precipitation is mostly due to decreased advection, which increases recycling (Dominguez and Kumar 2008). However, for severe droughts, this negative recycling feedback effectively shuts down, and therefore, local evapotranspiration ceases to contribute to precipitation.

We show that CFSv2 forecasts failed to capture different aspects of the drought events considered, especially in the Upper Midwest. The ensemble mean precipitation from the forecasts was close to the analysis for Texas, while significant overestimation was evident in the case of the Upper Midwest. Both recycled and advected components of precipitation were overestimated. For evapotranspiration as well, the forecasts showed large overestimation. We argue that the lack of detailed process representations in the Noah land surface model within the CFSv2 system might have played a key role in causing the poor performance of the forecasts. Thus, more detailed simulations of the terrestrial processes can potentially improve the CFS forecasts. The errors in the forecasting of atmospheric circulation patterns several weeks in advance can contribute to the misrepresentation of advection in the atmospheric component of the modeling system.

Clearly, it is not straightforward to pinpoint the exact solutions to the existing problems within the modeling system without a comprehensive set of controlled experiments. This is an interesting research area where more work is needed. The models need to be tested rigorously to select the best combination of the parameterizations for the problem in hand. Within a given coupled model, the land surface component needs to be improved taking into account the inconsistencies that come therein (Liu et al. 2017; Dirmeyer et al. 2018). A multimodel assessment can better address the issue of model structural uncertainty. Uncertainties arising from the choice of the input variables and initial and boundary conditions also need to be taken into account. In our case, although the precipitation fields from different products matched quite well (Fig. 2), there could still be discrepancies in other variables. More research will also be needed to extend the forecast comparison to a more detailed investigation of forecasting skill measured by different metrics at different initialization and lead times. Although many of these additional analyses were beyond the scope of this particular study, we hope that at the very least, our study provides some useful insights on the existing problems by looking at droughts from the perspective of atmospheric water partitioning by precipitation recycling and sheds some light on the potential solutions.

Acknowledgments. Financial support for this research was provided by the NOAA Grant NA14OAR4310236 (Understanding the Role of Land-Atmospheric Coupling in Drought Forecast Skill for the 2011 and 2012 US Droughts). Alexis Berg was supported by NOAA Grant NA15OAR4310091. Rongqian Yang from NCEP helped in transferring the CFSv2 forecasts data to Princeton server. MSWEP precipitation data were obtained from Hylke Beck, and Ming Pan provided the NLDAS2 precipitation data. Other members of the Terrestrial Hydrology Research Group at Princeton University provided valuable feedback throughout the course of this research. CFS datasets are available from NOAA/ NCDC. The authors express no conflict of interest.

\section{REFERENCES}

Agudelo, J., P. A. Arias, S. C. Vieira, and J. A. Martínez, 2018: Influence of longer dry seasons in the Southern Amazon on patterns of water vapor transport over northern South America and the Caribbean. Climate Dyn., https://doi.org/ 10.1007/s00382-018-4285-1, in press.

Anyah, R. O., C. P. Weaver, G. Miguez-Macho, Y. Fan, and A. Robock, 2008: Incorporating water table dynamics in 
climate modeling: 3. Simulated groundwater influence on coupled land-atmosphere variability. J. Geophys. Res., 113, D07103, https://doi.org/10.1029/2007JD009087.

Beck, H. E., A. I. J. M. Van Dijk, V. Levizzani, J. Schellekens, D. G. Miralles, B. Martens, and A. De Roo, 2017: MSWEP: 3-hourly $0.25^{\circ}$ global gridded precipitation (19792015) by merging gauge, satellite, and reanalysis data. $\mathrm{Hy}$ drol. Earth Syst. Sci., 21, 589-615, https://doi.org/10.5194/ hess-21-589-2017.

—, E. F. Wood, M. Pan, C. K. Fisher, D. G. Miralles, A. I. J. M. van Dijk, T. R. McVicar, and R. F. Adler, 2019: MSWEP V2 global 3-hourly $0.1^{\circ}$ precipitation: Methodology and quantitative assessment. Bull. Amer. Meteor. Soc., https://doi.org/ 10.1175/BAMS-D-17-0138.1, in press.

Bisselink, B., and J. Dolman, 2008: Precipitation recycling: Moisture sources over Europe using ERA-40 data. J. Hydrometeor., 9, 1073-1083, https://doi.org/10.1175/2008JHM962.1.

Bo, Z., S. Islam, and E. A. B. Eltahir, 1994: Aggregationdisaggregation properties. Water Resour. Res., 30, 34233435, https://doi.org/10.1029/94WR02026.

Boyer, J. S., and Coauthors, 2013: The U.S. drought of 2012 in perspective: A call to action. Global Food Secur., 2, 139-143, https://doi.org/10.1016/j.gfs.2013.08.002.

Brubaker, K. L., D. Entekhabi, and P. S. Eagleson, 1993: Estimation of continental precipitation recycling. J. Climate, $\mathbf{6}$, 1077-1089, https://doi.org/10.1175/1520-0442(1993)006<1077: EOCPR $>2.0 . \mathrm{CO} ; 2$.

Budyko, M. I., 1974: Climate and Life. D. H. Miller, Ed., International Geophysics Series, Vol. 18, Academic Press, $508 \mathrm{pp}$.

Burde, G. I., and A. Zangvil, 2001: The estimation of regional precipitation recycling. Part I: Review of recycling models. J. Climate, 14, 2497-2508, https://doi.org/10.1175/1520-0442 (2001) $014<2497$ :TEORPR $>2.0$. CO;2.

Daly, C., R. P. Neilson, and D. L. Phillips, 1994: A statisticaltopographic model for climatological precipitation over mountainous terrain. J. Appl. Meteor., 33, 140-158, https://doi.org/ 10.1175/1520-0450(1994)033<0140:ASTMFM >2.0.CO;2.

DeAngelis, A., F. Dominguez, Y. Fan, A. Robock, M. D. Kustu, and D. Robinson, 2010: Evidence of enhanced precipitation due to irrigation over the Great Plains of the United States. J. Geophys. Res., 115, D15115, https://doi.org/10.1029/ 2010JD013892.

Dee, D. P., and Coauthors, 2011: The ERA-Interim reanalysis: Configuration and performance of the data assimilation system. Quart. J. Roy. Meteor. Soc., 137, 553-597, https://doi.org/ 10.1002/qj.828.

Dirmeyer, P. A., and K. L. Brubaker, 2007: Characterization of the global hydrologic cycle from a back-trajectory analysis of atmospheric water vapor. J. Hydrometeor., 8, 20-37, https:// doi.org/10.1175/JHM557.1.

_- , and Coauthors, 2016: Confronting weather and climate models with observational data from soil moisture networks over the United States. J. Hydrometeor., 17, 1049-1067, https://doi.org/10.1175/JHM-D-15-0196.1.

— , and Coauthors, 2018: Verification of land-atmosphere coupling in forecast models, reanalyses, and land surface models using flux site observations. J. Hydrometeor., 19 , 375-392, https://doi.org/10.1175/JHM-D-17-0152.1.

Dominguez, F., and P. Kumar, 2008: Precipitation recycling variability and ecoclimatological stability -A study using NARR Data. Part I: Central U.S. plains ecoregion. J. Climate, 21, 5165-5186, https://doi.org/10.1175/2008JCLI1756.1.
, X. Z. Liang, and M. Ting, 2006: Impact of atmospheric moisture storage on precipitation recycling. J. Climate, 19, 1513-1530, https://doi.org/10.1175/JCLI3691.1.

,-- , and E. R. Vivoni, 2008: Precipitation recycling variability and ecoclimatological stability -A study using NARR data. Part II: North American monsoon region. J. Climate, 21, 5187-5203, https://doi.org/10.1175/2008JCLI1760.1.

, J. C. Villegas, and D. D. Breshears, 2009: Spatial extent of the North American Monsoon: Increased cross-regional linkages via atmospheric pathways. Geophys. Res. Lett., 36, L07401, https://doi.org/10.1029/2008GL037012.

Findell, K. L., and E. A. B. Eltahir, 2003: Atmospheric controls on soil moisture-boundary layer interactions. Part I: Framework development. J. Hydrometeor., 4, 552-569, https://doi.org/ 10.1175/1525-7541(2003)004<0552:ACOSML>2.0.CO;2.

Gimeno, L., and Coauthors, 2012: Oceanic and terrestrial sources of continental precipitation. Rev. Geophys., 50, RG4003, https://doi.org/10.1029/2012RG000389.

Goessling, H. F., and C. H. Reick, 2013: On the "well-mixed" assumption and numerical 2-D tracing of atmospheric moisture. Atmos. Chem. Phys., 13, 5567-5585, https://doi.org/10.5194/ acp-13-5567-2013.

Grigg, N. S., 2014: The 2011-2012 drought in the United States: New lessons from a record event. Int. J. Water Resour. Dev., 30, 183-199, https://doi.org/10.1080/07900627.2013.847710.

Herrera-Estrada, J. E., 2017: Advances in understanding the causes and impacts of droughts in North America under current and future climates. Ph.D. dissertation, Princeton University, 169 pp., https://pqdtopen.proquest.com/pubnum/10637641.html.

_ Y. Satoh, and J. Sheffield, 2017: Spatiotemporal dynamics of global drought. Geophys. Res. Lett., 44, 2254-2263, https:// doi.org/10.1002/2016GL071768.

Hoerling, M., J. Eischeid, A. Kumar, R. Leung, A. Mariotti, K. Mo, S. Schubert, and R. Seager, 2014: Causes and predictability of the 2012 great plains drought. Bull. Amer. Meteor. Soc., 95, 269-282, https://doi.org/10.1175/BAMS-D-13-00055.1.

Hua, L., L. Zhong, and Z. Ke, 2016: Precipitation recycling and soil-precipitation interaction across the arid and semi-arid regions of China. Int. J. Climatol., 36, 3708-3722, https://oi.org/ 10.1002/joc. 4586 .

,-- , and -2017 : Characteristics of the precipitation recycling ratio and its relationship with regional precipitation in China. Theor. Appl. Climatol., 127, 513-531, https://doi.org/ 10.1007/s00704-015-1645-1.

Jiang, X., G. Y. Niu, and Z. L. Yang, 2009: Impacts of vegetation and groundwater dynamics on warm season precipitation over the Central United States. J. Geophys. Res., 114, D06109, https://doi.org/10.1029/2008JD010756.

Kam, J., J. Sheffield, and E. F. Wood, 2014: A multiscale analysis of drought and pluvial mechanisms for the Southeastern United States. J. Geophys. Res. Atmos., 119, 7348-7367. https://doi.org/10.1002/2014JD021453.

Karl, T. R., and Coauthors, 2012: U.S. temperature and drought: Recent anomalies and trends. Eos, Trans. Amer. Geophys. Union, 93, 473-496, https://doi.org/10.1029/2012EO470001.

Kobayashi, S., and Coauthors, 2015: The JRA-55 Reanalysis: General specifications and basic characteristics. J. Meteor. Soc. Japan Ser. II, 93, 5-48, https://doi.org/10.2151/ jmsj.2015-001.

Koster, R. D., Z. Guo, R. Yang, P. A. Dirmeyer, K. Mitchell, and M. J. Puma, 2009: On the nature of soil moisture in land surface models. J. Climate, 22, 4322-4335, https://doi.org/10.1175/ 2009JCLI2832.1. 
Liu, C., and Coauthors, 2017: Continental-scale convectionpermitting modeling of the current and future climate of North America. Climate Dyn., 49, 71-95, https://doi.org/ 10.1007/s00382-016-3327-9.

Mallya, G., L. Zhao, X. C. Song, D. Niyogi, and R. S. Govindaraju, 2013: 2012 Midwest Drought in the United States. J. Hydrol. Eng., 18, 737-745, https://doi.org/10.1061/ (ASCE)HE.1943-5584.0000786.

Martinez, A. J., and F. Dominguez, 2014: Sources of atmospheric moisture for the La Plata River Basin. J. Climate, 27, 67376753, https://doi.org/10.1175/JCLI-D-14-00022.1.

Mei, R., M. Ashfaq, D. Rastogi, L. R. Leung, and F. Dominguez, 2015: Dominating controls for wetter South Asian summer monsoon in the twenty-first century. J. Climate, 28, 3400-3419, https://doi.org/10.1175/JCLI-D-14-00355.1.

Mitchell, K. E., 2004: The multi-institution North American Land Data Assimilation System (NLDAS): Utilizing multiple GCIP products and partners in a continental distributed hydrological modeling system. J. Geophys. Res., 109, D07S90, https://doi.org/ 10.1029/2003JD003823.

Nielson-Gammon, J. W., 2012: The 2011 Texas drought. Tex. Water J., 3 (1), 59-95.

Pathak, A., S. Ghosh, J. A. Martinez, F. Dominguez, and P. Kumar, 2017: Role of oceanic and land moisture sources and transport in the seasonal and interannual variability of summer monsoon in India. J. Climate, 30, 1839-1859, https://doi.org/10.1175/JCLID-16-0156.1.

Rienecker, M. M., and Coauthors, 2011: MERRA: NASA's Modern-Era Retrospective Analysis for Research and Applications. J. Climate, 24, 3624-3648, https://doi.org/10.1175/ JCLI-D-11-00015.1.

Roundy, J. K., C. R. Ferguson, and E. F. Wood, 2013: Temporal variability of land-atmosphere coupling and its implications for drought over the southeast United States. J. Hydrometeor., 14, 622-635, https://doi.org/10.1175/JHM-D-12-090.1.

Saha, S., and Coauthors, 2006: The NCEP Climate Forecast System. J. Climate, 19, 3483-3517, https://doi.org/10.1175/ JCLI3812.1.

— , and Coauthors, 2014: The NCEP Climate Forecast System version 2. J. Climate, 27, 2185-2208, https://doi.org/10.1175/ JCLI-D-12-00823.1.

Savenije, H. H. G., 1995: New definitions for moisture recycling and the relationship with land-use changes in the Sahel.
J. Hydrol., 167, 57-78, https://doi.org/10.1016/0022-1694(94) 02632-L.

Schär, C., D. Lüthi, U. Beyerle, and E. Heise, 1999: The soilprecipitation feedback: A process study with a regional climate model. J. Climate, 12, 722-741, https://doi.org/10.1175/ 1520-0442(1999)012<0722:TSPFAP $>2.0 . C O ; 2$.

Schubert, S. D., M. J. Suarez, P. J. Pegion, R. D. Koster, and T. Bacmeister, 2004: On the cause of the 1930s Dust Bowl. Science, 303, 1855-1859, https://doi.org/10.1126/science.1095048.

Seager, R., L. Goddard, J. Nakamura, N. Henderson, and D. E. Lee, 2014: Dynamical causes of the 2010/11 Texas-northern Mexico drought. J. Hydrometeor., 15, 39-68, https://doi.org/ 10.1175/JHM-D-13-024.1.

Trenberth, K. E., 1999: Atmospheric moisture recycling: Role of advection and local evaporation. J. Climate, 12, 1368-1381, https://doi.org/ 10.1175/1520-0442(1999)012<1368:AMRROA>2.0.CO;2.

Van Der Ent, R. J., and H. H. G. Savenije, 2013: Oceanic sources of continental precipitation and the correlation with sea surface temperature. Water Resour. Res., 49, 3993-4004, https://doi.org/10.1002/wrcr.20296.

Wang, H., R. Fu, A. Kumar, and W. Li, 2010: Intensification of summer rainfall variability in the southeastern United States during recent decades. J. Hydrometeor., 11, 1007-1018, https:// doi.org/10.1175/2010JHM1229.1.

Wimmers, A. J., and C. S. Velden, 2011: Seamless advective blending of total precipitable water retrievals from polarorbiting satellites. J. Appl. Meteor. Climatol., 50, 1024-1036, https://doi.org/10.1175/2010JAMC2589.1.

Yang, Z.-L., and Coauthors, 2011: The community Noah land surface model with multiparameterization options (NoahMP): 2. Evaluation over global river basins. J. Geophys. Res., 116, D12110, https://doi.org/10.1029/2010JD015140.

Zangvil, A., D. H. Portis, and P. J. Lamb, 2004: Investigation of the large-scale atmospheric moisture field over the midwestern United States in relation to summer precipitation. Part II: Recycling of local evapotranspiration and association with soil moisture and crop yields. J. Climate, 17, 3283-3301, https://doi.org/10.1175/1520-0442(2004)017<3283: IOTLAM $>2.0 . \mathrm{CO} ; 2$.

Ziese, M., and Coauthors, 2014: The GPCC Drought Index - A new, combined and gridded global drought index. Earth Syst. Sci. Data, 6, 285-295, https://doi.org/10.5194/essd-6285-2014. 